\title{
Epidemiology of Eye Injuries Resulting in Hospitalization, a Referral Hospital-Based Study
}

This article was published in the following Dove Press journal: Clinical Ophthalmology

Janejit Choovuthayakorn (DD Varisaporn Worakriangkrai

Direk Patikulsila (ID

Nawat Watanachai (D)

Paradee Kunavisarut

Voraporn Chaikitmongkol

Dao Luewattananont (D)

Napaporn Tananuvat

Department of Ophthalmology, Faculty of Medicine, Chiang Mai University, Chiang

Mai, Thailand
Correspondence: Janejit

Choovuthayakorn

Department of Ophthalmology, Faculty of

Medicine, Chiang Mai University, IIO

Intavaroros Road, Muang, Chiang Mai

50200, Thailand

Tel +6653935512

Fax +6653936121

Email janejit.c@cmu.ac.th
Purpose: To determine the characteristics of hospitalized eye injuries in Northern Thailand, a tertiary referral center.

Methods: The medical records of patients who sustained an eye injury and were admitted to the Department of Ophthalmology, Chiang Mai University, Thailand, from February 2015 to February 2016 were retrospectively reviewed. Demographics and characteristics of each injury were collected.

Results: A total of 249 injured patients were included, of which 227 (91.2\%) were male. There was no significant difference in the mean (standard deviation) age between genders, 39.8 (22.9) years of age for females and 43.8 (17.8) for males $(P=0.43)$. Most injuries occurred in the workplace $(149 / 249,59.8 \%)$. Nearly similar proportions of the opened globe and closed globe injuries were observed, $121 / 249$ (48.6\%) patients and 109/249 (43.8\%) patients. A small proportion sustained eyelid/adnexal and chemical injury, 19/249 (7.6\%) patients. Corneal penetration $(52 / 249,20.9 \%)$ and intraocular foreign body (37/249 14.9\%) were the most prevalent conditions for opened globe injury. Traumatic lens subluxation/ dislocation $(31 / 249,12.4 \%)$ and a traumatic corneal ulcer $(25 / 249,10.1 \%)$ were the common conditions for closed globe injury. A delayed presentation to the hospital was noted in closed globe injury. The eyelid/adnexal injury group had a better final visual acuity compared to the opened and closed globe injury group.

Conclusion: Activities related to hospitalized eye injuries were varied in different age groups, specifically adults at workplace, and children at playground; therefore different strategies should be applied to prevent visual impairments and disabilities in specific high-risk groups.

Keywords: ocular trauma, ocular injury, admission, hospitalization

\section{Introduction}

Eye injury is an important worldwide condition leading to acquired severe monocular visual impairment in all age groups. A significant number of these patients sustained a severe injury and required hospital admission for either medical and/or surgical management with the reported incidence rate ranging from 8.6 to 89 per 100,000 population-years. ${ }^{1-5}$ A need for hospitalization along with a subsequent severe visual disability increased the burden to both the family and the economic health care system. Therefore, eye injury prevention programs are important public health concerns that should be put forward. However, epidemiology and characteristics of hospitalized eye injury had considerable discrepancies between publications depending on ethnic, culture, or daily living patterns of each population. ${ }^{3-6}$ The lack of information regarding eye injury types, mechanisms, activities or causative objects leads to an inability to determine effective preventive strategies. 
This study aimed to evaluate the epidemiology of severe eye injury in individuals who required admission to an ophthalmology department of a tertiary eye care center in Northern Thailand. The results may provide an impact on implementation and targeting interventions to decrease or prevent these eye injuries.

\section{Materials and Methods}

This retrospective cohort study collected the data from all ocular injury patients admitted to the Ophthalmology Department, Chiang Mai University Hospital, between February 1, 2015, and February 29, 2016. The protocol was studied in accordance with the tenets of the Declaration of Helsinki and was approved by the Hospital Research Ethics Committee, Faculty of Medicine, Chiang Mai university. The need for patient consent was waived in light of the retrospective design, and a de-identified nature of data collected with a low risk of confidentiality breach. The medical records were anonymized and captured by two of the authors (JC, VW), using a standardized record form to guide data collection. To settle the ambiguous or conflicting data, open adjudication between the reviewers was performed. Variables including the demographics of patients, location, type, activity, and frequency related to each eye injury were reviewed. Ocular characteristics, diagnosis, and management were collected. Visual outcomes at the final follow-up were observed. In cases with bilateral eye injuries, the eye with more visual impairment at presentation was included for clinical and outcome evaluation. A Birmingham Eye Trauma Terminology (BETT) system and a modified system were applied for the globe, orbital and adnexal-related injury classifications. ${ }^{7,8}$

\section{Statistical Analysis}

For a continuous variable, mean and standard deviation (SD) or median and interquartile range (IQR) was described. A comparison of continuous data between groups was performed by $t$-test, one-way ANOVA or Kruskal-Wallis test as appropriate for data distribution. A categorical variable was analyzed by chi-square or Fisher exact test. A $P$ value of less than 0.05 was considered significant. Statistical analysis was performed with the SPSS program, version 16.0 (SPSS Inc., Chicago, USA).

\section{Results}

A total of 249 patients, with a median (range) follow-up period of 7.8 (3-14) months, were included in this study. Two hundred and twenty-seven (91.2\%) were males with an age range from 2 to 79 years, while $22(8.8 \%)$ were females with an age range from 1 to 76 years. No significant difference in the mean age between genders was detected $(P=0.43)$. Three cases $(1.2 \%)$ had bilateral eye injuries, one sustained a chemical injury and two sustained vehicle accidents. The 40 to 60 -year-old age group represented a peak proportion of admitted eye injuries in both genders (Figure 1). Elderly aged 60 and over accounted for $5 / 22(22.7 \%)$ for females and 46/227 (20.3\%) for males, $P=0.78$. Demographics and characteristics of eye injuries requiring admission are shown in Table 1.

Of 227 males, $144(63.4 \%)$ sustained an injury at the workplace, followed by home $(35,15.4 \%)$ and street $(32$, $14.1 \%)$. In contrast, females mostly encountered injuries in the street $(8 / 22,36.4 \%)$, followed by home $(6 / 22,27.3 \%)$, and at the workplace $(5 / 22,27.3 \%)$, respectively. Regarding the specific age groups, eye injuries predominantly occurred from unintentional hitting/piercing by wooden objects in young children aged less than 15 years, transportation accidents in the group aged 15 to 40 years, flying objects from electric grass trimmer in middle-age adults (aged 40 to 60 years), and by wooden objects in the elderly group (age more than 60 years). The distribution of activities/objects leading to eye injuries across age groups is summarized in Table 2.

For types of eye injury, opened and closed globe injuries occurred in 121/249 (48.6\%) and 109/249 (43.8\%) of patients who were hospitalized. Even though a non-significant difference in the distribution of injury types by specific age groups was noted $(P=0.07)$, closed globe injury tended to have a higher proportion in an older age group as shown in Figure 2. Corneal penetration $(52 / 249,20.9 \%)$ and intraocular foreign body (IOFB) (37/249 14.9\%) were the two most frequent conditions of opened globe injuries, while traumatic lens subluxation/dislocation $(31 / 249,12.4 \%)$, traumatic corneal ulcer $(25 / 249,10.1 \%)$, and traumatic optic neuropathy

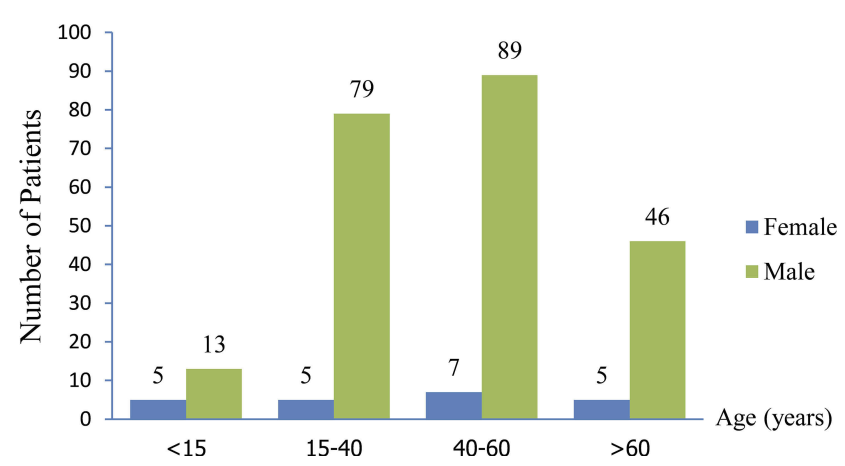

Figure I Frequency of eye injuries requiring admission according to gender and age groups. 
Table I Demographic and Characteristics of Hospitalized Eye Injuries Patients

\begin{tabular}{|l|l|}
\hline Characteristics & \\
\hline $\begin{array}{l}\text { Age, mean (SD), years } \\
\text { Male }\end{array}$ & \\
Female & $43.8(17.8)$ \\
\hline Laterality (right/left), N & $39.8(22.9)$ \\
\hline Types of eye injuries, N (\%) & $130 / 119$ \\
Opened globe (N=I2I) & \\
Penetration & \\
Rupture & $52(20.9)$ \\
Intraocular foreign bodies & $28(11.2)$ \\
Perforation & $37(14.9)$ \\
Closed globe (N= 109) & $4(1.6)$ \\
Contusion & \\
Lamellar laceration & $81(32.5)$ \\
Eyelid/adnexal injuries & $28(I 1.3)$ \\
Chemical injuries & $18(7.2 \%)$ \\
Place of the injury & $1(0.4 \%)$ \\
In the province & \\
Other provinces & $79(32.9)$ \\
& $170(67.1)$ \\
\hline
\end{tabular}

$(15 / 249,6.0 \%)$ were the most common conditions of closed globe injuries.

Characteristics of hospitalization by injury types are demonstrated in Table 3. Considering a time interval before arriving at hospital, the proportion of patients who presented to a hospital longer than $72 \mathrm{hrs}$ following injuries was 17 $(15.6 \%)$ in closed globe injury, $10(8.3 \%)$ in opened globe injury, and one (5.3\%) in the eyelid/adnexal injury group, $P=$ 0.01 . Medical management was provided for 41 (16.5\%) of all admitted patients, while surgical management was performed in 208 (83.5\%) cases. Among 234 patients (94\%) that

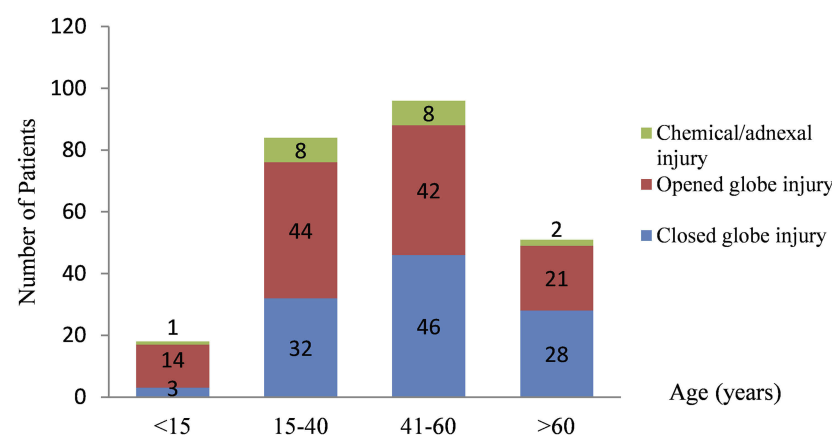

Figure 2 Distribution of types of eye injury by age groups.

the initial visual acuity (VA) could be evaluated, the eyelid/ adnexal injury group attained a better initial VA than the opened and closed globe injury groups. A proportion of final visual acuity of 20/400 and better was highest in the eyelid/adnexal injury group, $P=0.01$. In accordance, a proportion of final no light perception vision was 10 $(9.5 \%)$ in the opened globe injury group, $16(13.4 \%)$ in the closed globe injury group, and none in the eyelid/adnexal injury group. The distribution of the initial VA and final VA is shown in Figure 3.

\section{Discussion}

This study demonstrated the patterns of eye injury requiring hospital admission in a tertiary referral center of Northern Thailand. Injuries related to wooden objects were a major concern, which accounted for approximately one-fifth of overall causes. The longer time interval before presentation to a hospital was noted in a closed globe injury compared to opened globe injury group. A favorable final visual acuity was more frequent among

Table 2 Distribution of Activities and Objects Related to Hospitalized Eye Injury by Age Groups

\begin{tabular}{|c|c|c|c|c|}
\hline $\begin{array}{l}\text { Activities/Objects } \\
\mathbf{N}(\%)\end{array}$ & $\begin{array}{l}\text { Less Than } 15 \text { Years } \\
N=18\end{array}$ & $\begin{array}{l}\text { I } 5 \text { to } 40 \\
\text { Years } \\
N=84\end{array}$ & $\begin{array}{l}41 \text { to } 60 \\
\text { Years } \\
N=96\end{array}$ & $\begin{array}{l}\text { More Than } 60 \text { Years } \\
N=51\end{array}$ \\
\hline Hit/stabbing by wooden object & $6(33.3)$ & $8(9.5)$ & $18(18.7)$ & $18(35.3)$ \\
\hline Hit by transportation related object & I (5.6) & $23(27.4)$ & $13(13.5)$ & $3(5.9)$ \\
\hline $\begin{array}{l}\text { Hit by flying object from electric grass } \\
\text { trimmer }\end{array}$ & I (5.6) & $8(9.5)$ & $23(23.9)$ & $7(13.7)$ \\
\hline Hit/stabbing by nail/stone & I (5.6) & $5(5.9)$ & $14(14.6)$ & $5(9.8)$ \\
\hline Piercing by organic plant & $0(0)$ & $5(5.9)$ & $7(7.3)$ & $4(7.8)$ \\
\hline Hit by metallic object & I (5.6) & $12(14.3)$ & $3(3.1)$ & $7(13.7)$ \\
\hline Fall & $3(16.6)$ & $3(3.6)$ & $3(3.1)$ & $3(5.9)$ \\
\hline Others & $5(27.7)$ & $20(23.8)$ & I5 (I5.8) & $4(7.8)$ \\
\hline
\end{tabular}


Table 3 Characteristics of Hospitalization by Types of Eye Injury

\begin{tabular}{|c|c|c|c|c|}
\hline & $\begin{array}{l}\text { Closed } \\
\text { Globe Injury }\end{array}$ & $\begin{array}{l}\text { Opened } \\
\text { Globe Injury }\end{array}$ & $\begin{array}{l}\text { Eyelid and Adnexal and } \\
\text { Injury }\end{array}$ & $P$ value \\
\hline Duration before admission, hour, median (range) & $22(1-720)$ & $4(I-2 \mid 3)$ & $9(1-150)$ & $<0.001$ \\
\hline Initial Snellen VA, N (\%) & & & & $<0.001$ \\
\hline $20 / 200$ and better & $30(28.6)$ & $21(18.3)$ & $12(85.7)$ & \\
\hline Worse than $20 / 200$ & $75(71.4)$ & $94(81.7)$ & $2(14.3)$ & \\
\hline Length of hospitalization, $\mathrm{N}$ (\%) & & & & 0.418 \\
\hline 2 weeks and less & $94(86.2)$ & III (9I.7) & $17(89.5)$ & \\
\hline More than 2 weeks & $15(13.8)$ & $10(8.3)$ & $2(10.5)$ & \\
\hline
\end{tabular}

Abbreviation: VA, visual acuity.

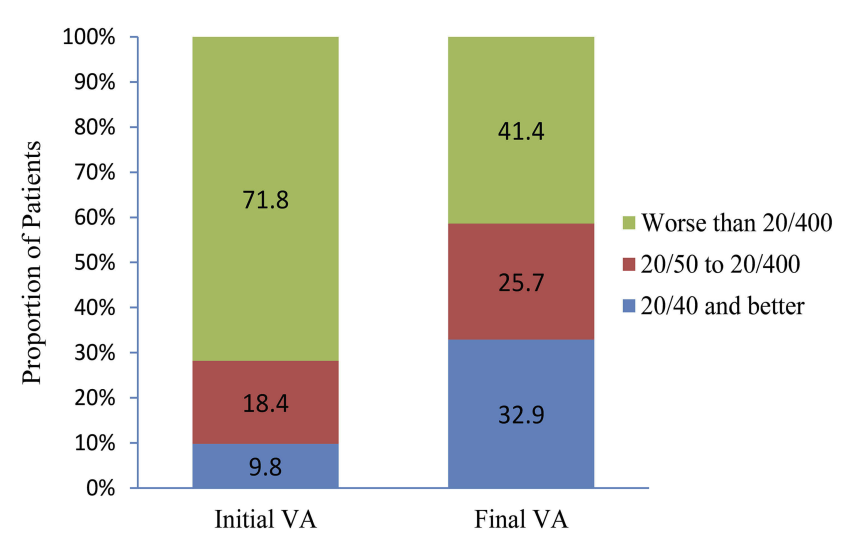

Figure 3 Proportion of presenting and final visual acuity.

adnexal injuries than in the closed and opened globe injuries.

Consistent with other publications, this study observed that males were a more vulnerable gender for hospitalized eye injury, regardless of requiring medical treatment and/or surgical intervention, compared to females. ${ }^{4-6,9-11}$ However, the difference in patterns of age distribution among genders was noted. A study in South-Central China by Wang et al reported that the most prevalent eye injuries in males were distributed in the 41 to 50-year-old age group, while in a range of 1 to 10 -year-old in females. ${ }^{5}$ A study in Taiwan by Lee et al showed that males had a high risk of principal eye trauma in a plateau age range from 30 to 79 years, whereas two peaks of risky age groups, 30 to 39 and 70 to 79 years, were shown in females. ${ }^{4}$ This study found that individuals aged 40 to 60 years attained the highest incidence of eye injuries requiring admission than other age groups in both genders. These dissimilarities presumably reflect a difference in lifestyle, cultural environment or occupational pattern of each gender between regions.

Apart from gender, age is another influencing factor that is associated with an eye injury. Activities leading to an eye injury in specific age groups have been variously described in prior studies. For children, a high proportion of eye injury was related to playing, either by self-infliction or by another person, and eye injuries caused by sharp implement objects have been proposed. ${ }^{5,12-16}$ Similarly, this study observed that an unintentional hitting by sharp wooden objects was a prominent cause for eye injury in patients less than 15 years of age. This may be in part due to the immature nature of young children and possibly a need for more attention from caretakers while children play or use sharp wooden objects. A safety education targeting both supervision adults and young children while handling potentially risky objects in daily activities may help to diminish the incidence of eye injuries in this subgroup. In addition, even though some injuries are difficult to prevent, safety environment management would be another simple strategy to further prevent a serious eye injury in the young.

The importance of transportation accidents on eye injury has been widely reported. A study by Cillino et al showed that road accidents were more likely to occur in urban than in rural areas. ${ }^{17}$ Zhang et al reported that most of the vehicle-related accidents occurred in patients ranging from 15 to 29 years. ${ }^{14}$ A study from Taiwan reported that traffic accidents accounted for the most common causes of principal and secondary diagnosis of hospitalized eye trauma. ${ }^{4}$ Concordant to previous reviews, this study found that transportation accidents were the major contributors to eye injuries in young adults (between 15 and 40 years). ${ }^{2,14}$ This trend is likely to be explained by the tendency for younger adults to engage in transportation activities with less ability or experience to recognize hazardous situations than more mature adults. Consequently, it is crucial to pay attention to a need for effective preventive education and a stringent implementation regarding transportation among these young adults. Additionally, compliance with safety guidelines should be regularly assessed. In adults, the 
incidence of hospitalized eye injury was different from that in teenagers. Several studies indicated occupational related eye injury was the major cause with differences in work types between countries. ${ }^{18-20}$ This study highlighted that a high number of eye injury occurred in 40 to 60 years old age group during work that involved an electric grass trimmer. This may in part reflect the low rate of using eye-protective equipment when undertaking high-risk work. Even though safety eyewear protection is a requirement in the workplace, a low usage rate was reported, especially in agricultural work. $^{21}$ Significant barriers about using protective eyewear including impairment of vision, discomfort or shyness were reported. ${ }^{22,23}$ It is important that a program raising awareness is needed for workers regarding the risk of severe visual loss and to motivate attention to safety when performing any work. To deliver our essential findings regarding eye injuries and also the possible preventive measurements, the use of social media platforms is of significant contributions. In the elderly, while falls represented a prominent situation for eye injury requiring admission in the US and Taiwan, this study pointed out the importance of activities related to wooden objects. ${ }^{3,4}$ This may be explained by differences in characteristics in the socioeconomic system between populations which results in differences in the daily activity of the elderly.

Noticeably, this study revealed a shorter time duration before seeking for ophthalmic evaluation and management in opened globe compared to closed globe injury. This concern may relate to negligible attention following a minor superficial lamellar laceration of the eyewall and adnexal tissue, especially from agricultural work. This laceration may later progress to a severe corneal laceration. Studies regarding agricultural work-related eye injury in developing countries have been demonstrated and the importance of infected corneal abrasion has been emphasized. ${ }^{24,25}$ The significant proportion of traumatic corneal ulcers in this study provided essential information regarding a lack of understanding and appropriate care in patients who came in contact with organic materials. Community education concerning appropriate protective eyewear use and a prompt evaluation following eye injury need to be addressed in ophthalmic health education programs.

This study has limitations due to the retrospective review procedure. The lack of a consistent definition of location or mechanism of ocular trauma in the medical records may lead to an under or overestimation of an incident. Second, some multiple injury patients who were primarily admitted to the non-ophthalmic department might not be reviewed in this study. Additionally, only serious eye injuries may require hospitalization, making it difficult to estimate minor eye injuries in this study. Lastly, the final visual acuity information may not be precisely recognized due to a proportion of patients who denied either primary or secondary management. Apart from these drawbacks, this study provides useful information regarding patterns of eye injury in a tertiary-based center.

\section{Conclusion}

Adult males remain the most susceptible population for hospitalized eye injuries. Most injuries occurred during work, especially with agricultural-related activities. Eye care programs targeting this high-risk group may effectively reduce visual impairment from eye injuries. An awareness of seeking eye care evaluation when sustaining eye trauma even though in closed globe situation should be emphasized to minimize a delayed in presentation. Therefore, the implementation of different preventive strategies for specific age groups should be focused.

\section{Acknowledgment}

This study received a supported fund from Faculty of Medicine, Chiang Mai University, Chiang Mai, Thailand.

\section{Disclosure}

The authors report no conflicts of interest in this work.

\section{References}

1. Saeed A, Khan I, Dunne O, Stack J, Beatty S. Ocular injury requiring hospitalisation in the south east of Ireland: 2001-2007. Injury. 2010;41 (1):86-91. doi:10.1016/j.injury.2009.01.118

2. Raymond S, Jenkins M, Favilla I, Rajeswaran D. Hospital-admitted eye injury in Victoria, Australia. Clin Exp Ophthalmol. 2010;38 (6):566-571. doi:10.1111/j.1442-9071.2010.02296.x

3. Iftikhar M, Latif A, Farid UZ, Usmani B, Canner JK, Shah SMA. Changes in the incidence of eye trauma hospitalizations in the United States from 2001 through 2014. JAMA Ophthalmol. 2019;137 (1):48-56. doi:10.1001/jamaophthalmol.2018.4685

4. Lee JS, Chiou MJ, Teng FL, See LC. The role of principal and secondary diagnoses of hospitalized eye trauma: a nationwide cohort in Taiwan, 1996-2010. PLoS One. 2015;10(4):e0123348. doi:10.1371/ journal.pone. 0123348

5. Wang W, Zhou Y, Zeng J, Shi M, Chen B. Epidemiology and clinical characteristics of patients hospitalized for ocular trauma in South-Central China. Acta Ophthalmol. 2017;95(6):e503-e510. doi:10.1111/aos.2017.95.issue-6

6. Movahedinejad T, Adib-Hajbaghery M, Zahedi MR. A study on hospital admissions for eye trauma in Kashan, Iran. Trauma Mon. 2016;21 (2):e28073. doi:10.5812/traumamon

7. Kuhn F, Morris R, Witherspoon CD, Mester V. The Birmingham Eye Trauma Terminology system (BETT). J Fr Ophtalmol. 2004;27 (2):206-210. doi:10.1016/S0181-5512(04)96122-0 
8. Xiao JH, Zhang MN, Li SY, et al. A new classification for epidemiological study of mechanical eye injuries. Chin J Traumatol. 2014;17(1):35-37.

9. AlMahmoud T, Al Hadhrami SM, Elhanan M, Alshamsi HN, AbuZidan FM. Epidemiology of eye injuries in a high-income developing country: an observational study. Medicine (Baltimore). 2019;98(26): e16083. doi:10.1097/MD.0000000000016083

10. Mowatt L, McDonald A, Ferron-Boothe D. Hospitalization trends in adult ocular trauma at the university hospital of the West Indies. West Indian Med J. 2012;61(6):605-609.

11. Qi Y, Zhang FY, Peng GH, et al. Characteristics and visual outcomes of patients hospitalized for ocular trauma in central China: 2006-2011. Int J Ophthalmol. 2015;8(1):162-168. doi:10.3980/j. issn.2222-3959.2015.01.29

12. Qayum S, Anjum R, Rather S. Epidemiological profile of pediatric ocular trauma in a tertiary hospital of northern India. Chin J Traumatol. 2018;21(2):100-103. doi:10.1016/j.cjtee.2017.11.005

13. Sii F, Barry RJ, Abbott J, Blanch RJ, MacEwen CJ, Shah P. The UK Paediatric Ocular Trauma Study 2 (POTS2): demographics and mechanisms of injuries. Clin Ophthalmol. 2018;12:105-111. doi:10.2147/OPTH

14. Zhang X, Liu Y, Ji X, Zou Y. A retrospective study on clinical features and visual outcome of patients hospitalized for ocular trauma in Cangzhou, China. J Ophthalmol. 2017;2017:7694913.

15. Bućan K, Matas A, Lovrić JM, et al. Epidemiology of ocular trauma in children requiring hospital admission: a 16-year retrospective cohort study. J Glob Health. 2017;7(1):010415. doi:10.7189/ jogh.07.010415

16. Saka ES, Monsudi KF, Olatuji V. Traumatic corneal laceration in northwestern Nigeria. J West Afr Coll Surg. 2017;7(4):72-84.

17. Cillino S, Casuccio A, Di Pace F, Pillitteri F, Cillino G. A five-year retrospective study of the epidemiological characteristics and visual outcomes of patients hospitalized for ocular trauma in a mediterranean area. BMC Ophthalmol. 2008;8:6. doi:10.1186/1471-2415-8-6
18. Jovanovic N, Peek-Asa C, Swanton A, et al. Prevalence and risk factors associated with work-related eye injuries in Bosnia and Herzegovina. Int J Occup Environ Health. 2016;22(4):325-332. doi:10.1080/10773525.2016.1243081

19. Cai M, Zhang J. Epidemiological characteristics of work-related ocular trauma in Southwest region of China. Int $J$ Environ Res Public Health. 2015;12(8):9864-9875. doi:10.3390/ijerph120809864

20. Gobba F, Dall'Olio E, Modenese A, De Maria M, Campi L, Cavallini GM. Work-related eye injuries: a relevant health problem. Main epidemiological data from a highly-industrialized area of Northern Italy. Int J Environ Res Public Health. 2017;14(6):604. doi:10.3390/ijerph14060604

21. Limbu B, Moore G, Marvasti AH, Poole ME, Saiju R. Work related ocular injury: Nepal. Nepal J Ophthalmol. 2018;10(19):47-56. doi:10.3126/nepjoph.v10i1.21689

22. Chatterjee S, Agrawal D. Primary prevention of ocular injury in agricultural workers with safety eyewear. Indian J Ophthalmol. 2017;65(9):859-864. doi:10.4103/ijo.IJO_334_17

23. Monaghan PF, Bryant CA, McDermott RJ, Forst LS, Luque JS, Contreras RB. Adoption of safety eyewear among citrus harvesters in rural Florida. J Immigr Minor Health. 2012;14(3):460-466. doi:10.1007/s10903-011-9484-3

24. Upadhyay MP, Karmacharya PC, Koirala S, et al. Epidemiologic characteristics, predisposing factors, and etiologic diagnosis of corneal ulceration in Nepal. Am J Ophthalmol. 1991;111(1):92-99. doi:10.1016/S0002-9394(14)76903-X

25. Thylefors B. Epidemiological patterns of ocular trauma. Aust N Z J Ophthalmol. 1992;20(2):95-98. doi:10.1111/ceo.1992.20. issue-2
Clinical Ophthalmology

\section{Publish your work in this journal}

Clinical Ophthalmology is an international, peer-reviewed journal covering all subspecialties within ophthalmology. Key topics include: Optometry; Visual science; Pharmacology and drug therapy in eye diseases; Basic Sciences; Primary and Secondary eye care; Patient Safety and Quality of Care Improvements. This journal is indexed on PubMed

\section{Dovepress}

Central and CAS, and is the official journal of The Society of Clinical Ophthalmology (SCO). The manuscript management system is completely online and includes a very quick and fair peer-review system, which is all easy to use. Visit http://www.dovepress.com/ testimonials.php to read real quotes from published authors. 